\title{
Final Project Report
}

August, 1998

Sponsoring Agency: Program for Ecosystem Research, Office of Energy Research, U. S. Department of Energy.

Project Number and Title: DE-FGO3-93-ER-6187, "Interactive Effects of Elevated $\mathrm{CO}_{2}$, Drought and High Temperature on Plant Water Use Efriciency"

Project Duration: Sept.1, 1993 to August 31, 1997

Investigators: Thẹodore C. Hsiao, PH, Hydrology Program.Tel. 916-752-0691, e-mail: tchsiao@uedavis.edu; K. T. Paw U, CoPI, Atmosphere Science Program, Tel. 916752-1510, e-mail: ktpawu@ucdavis.edu, Departwent of Land, Air, and Water Resonrces, University of California, Davis, CA 95616,

Theory and Objectives:

Water use efficiency (WUE) by plants is a key determant of productivity and survival of plants under water limiting or drought conditions. Anticipating the likely increases in temperature and frequency of drought with the coming climate change largely effected by the rising atmospheric carbon dioxide $\left(\mathrm{CO}_{2}\right)$, quantification of the potential changes in WUE is essential for the better prediction of future plant productivity and ability of plants to serve as sinks for $\mathrm{CO}_{2}$. WUE is known to be improved under elevated $\mathrm{CO}_{2}$. The extent of the improvement, however, varied widely from study to study in the literarure. The aim of this project was to develop a mechanistic basis for predicting WUE without the prolibitive task of studying every plant species under a range of environmental conditions. A data baso was to be developed for the application of a simple and newly evolved WUE framework (Hsiao, 1993) for single leaves in relation to $\mathrm{CO}_{2}$ levels and environmental stresses. The concept was be scaled up to the whole plant and canopy level through experimental work, and modeling and model verification. In this approach, the task was greatly simplified by using the ratio of $\mathrm{CO}_{2}$ concentration in the leaf intercellular space $\left(\mathrm{C}_{i}\right)$ to that in the 


\section{DISCLAIMER}

This report was prepared as an account of work sponsored by an agency of the United States Government. Neither the United States Government nor any agency thereof, nor any of their employees, make any warranty, express or implied, or assumes any legal liability or responsibility for the accuracy, completeness, or usefulness of any information, apparatus, product, or process disclosed, or represents that its use would not infringe privately owned rights. Reference herein to any specific commercial product, process, or service by trade name, trademark, manufacturer, or otherwise does not necessarily constitute or imply its endorsement, recommendation, or favoring by the United States Government or any agency thereof. The views and opinions of authors expressed herein do not necessarily state or reflect those of the United States Government or any agency thereof. 


\section{DISCLAIMER}

Portions of this document may be illegible in electronic image products. Images are produced from the best available original document. 
bulk air $\left(\mathrm{C}_{\mathfrak{a}}\right)$ as a key parameter in the quantification of $\mathrm{CO}_{2}$ assimilation $(\mathrm{A})$ rate and transpiration rate. This matio $\left(C_{j} / C_{a}\right)$, designated as $\alpha$, has been shown by a number of previous studies to have a tendency to stay constant or to vary with environmental or plant conditions in a relafively simple manner. Making use of the conservative behavior of $\alpha_{3}$ Hsiao (1993) was able to show that quite simple equations based on fundamental principles can be derived to predict the relative change in WUE of single leaves.

\section{Methods}

Experiments were conducted in growth chambers at different controlled levels of $\mathrm{CO}_{2}$, and in the field where $\mathrm{CO}_{2}$ level was anibient, but highly variable diumally. Effect of water and high temperature stress was also evaluated in the field. A water stress treatment was included while high temperature stress was studied taking advantage of the matural diurnally and day-to-day variations in temperature. Maize, cotton and soybean were grown in controlled environment chambers at the normal, $15 x$ and $2 x$ the normal $\mathrm{CO}_{2}$ concentrations, and their biomass and water use were measured at timed intervals, along with the measurement of air and leaf temperature. Concurrently, one plant was moved at a time to the laboratory for 6 to $8 \mathrm{~h}$ for the characterization of its leaf photosynthesis and stomata conductance in a steady state gas exchange apparatus, yielding curves of $A$ vs. $C_{i}$ and of photosynthesis response to environmental variables such as PAR (photosynthetically active radiation), temperature, and humidity, Maize and corton were also grown in the field in an area large enough (4 to 5 hectares) to ensure adequate fetch for the determination of evapotranspiration and canopy photosynthesis by micrometeorological methods. One half of the field was well irrigated, and the other half was subjected to water stress. The Bowen ratio/energy balance/ $\mathrm{CO}_{2}$ gradient technique $(\mathrm{BREB}+$ ) was used to monitor evapotranspiration, energy budget, and $\mathrm{CO}_{2}$ flux into the canopy of each half of the field. Associated measurements included canopy temperature, canopy light interception, leaf photosynthesis and conductance, leaf area, leaf water potential, respiration of non-leaf parts of the plant, shoot biomass, and soil water balance. For model validation and verification, additional data were collected on selected days in the field. These included data on turbulent statistics measured with sonic anemometers (including three dimensional); wind, temperature, $\mathrm{CO}_{2}$, and humidity profiles within and above the canopy. 


\section{Highlights of Regults}

Extensive data were obtained indicating that the ratio $(\alpha)$ of intercellular $\mathrm{CO}_{2}$ concentration $\left(C_{i}\right)$ to air $\mathrm{CO}_{2}$ concentration $\left(C_{0}\right)$ remains essentially constant over a range of air $\mathrm{CO}_{2}$ concentrations for maize, sorghum, and cotton, regardless whether grown at 360 or $720 \mathrm{ppm}$ of $\mathrm{CO}_{2}$, and that $\mathrm{C}_{\mathrm{i}}$ remains essentially constant over fairly wide range of PAR for cotton and maize. Small pots caused the plants to adjust photosynthesis capacity downward under high $\mathrm{CO}_{2}$ but did not significantly affect $\alpha$. The near constancy of $\alpha$ justifies the use of Hsiao's (1993) approach for the estimation of relative changes in WUE under elevated $\mathrm{CO}_{2}$. Mean biomass WUE of cotton was increased $89 \%$, in two growth

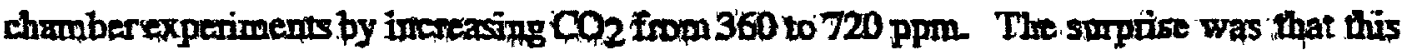
increase was predicted by a equation of Hsiao to within $3 \%$, using the air bunidity and leaf temperature data. Additional experiments in growth chambers verified the results. Field experiments showed biomass WUE of maize was not significantly affected by water $\$$ tress, and was relatively constant when normalized for evaporative demand. Extensive data were obtained with meteorological techniques on diumal and seasonal trends in canopy $\mathrm{CO}_{2}$ assimilation and evapotranspiration in the field, and on photosynthetic WUE. Detailed profiles of air $\mathrm{CO}_{2}$ concentration, humidity, and temperature within and above the canopies were also measured. These revealed that plants experience substantial fluctuations in their $\mathrm{CO}_{2}$ environment, which are sufficiently large to impact the rate of photosyrthesis and WUE. Hsiao' simple equation was also used to predict the relative changes in 5-min mean WUE of maize in the field over diumal cycles. The predictions turned out to be surprisingsly good. The equation used was developed for gas exchange of single leaves. The reason for the successful use of the equation at the whole plant (in growth chambers) and the community canopy level (field studies) is unclear, but the results do suggest that upscaling may not be a problem in the case of crop WUE. This exciting possibility of being able to predict WUE for different and changing $\mathrm{CO}_{2}$ and environmental conditions needs additional substantiation. A coupled stomatal control and photosynthesis model was formulated and integrated with a layered canopy higher order closuro model to simulate canopy response to $\mathrm{CO}_{2}$ concentrations environmental factors. This model has been compared with some of the more conventional models for the estimation of canopy photosynthesis and water use. The extensive field data collected on canopy photosynthesis, evapotranspiration, WUE, and profiles of $\mathrm{CO}_{3}$ and other meteorological parameters will be used to test the models further. 


\section{Gas Exchange Characteriatics}

Effect of growth $\mathrm{CO}_{2}$ level on assimilation and $\alpha$, A vs. $\mathrm{C}_{\mathrm{i}}$ curves showed that cotton leaves increased photosynthesis as $C_{i}$ was increased, to and beyond $400 \mathrm{ppm}$, corresponding to $C_{a}$ of about $700 \mathrm{ppm}$. Similar results were obtained with soybean. In contrast, maize leaf photosynthesis responded to increases in $\mathrm{C}_{\mathrm{i}}$ only at low levels of $\mathrm{C}_{\mathrm{i}}$ and was essentially saturated at $120 \mathrm{ppm}$, corresponding to a $\mathrm{Ca}_{\mathrm{a}}$ of about 450 to $500 \mathrm{ppm}$. Growth in $720 \mathrm{ppm}$ instead of $360 \mathrm{ppm}$ of $\mathrm{CO}_{2}$ did not change the $A$ vs. $\mathrm{C}_{\mathrm{i}}$ curves of maize. In contrast, for cotton the curve showed a slight reduction in $A$ at a given $C_{p}$, indicating a reduction in photosynthetic capacity when grown at $2 \times \mathrm{CO}_{2}$. The curves for soybean aiso appeared to be lower for the plants grown at $2 \pi \mathrm{CO}_{2}$, although the difference Wras too small to be certain.

More important is the ratio $\mathrm{C}_{\mathrm{i}} / \mathrm{C}_{2}$, a For colton (Fig, 1) and maize (Fig. 2), the ratio was essentially constant as $\mathrm{C}_{\mathrm{a}}$ varied over a wide range. For soybean (Fig, 3 ), the ratio appeared to be higher at $\mathrm{C}_{2}<300 \mathrm{ppm}$, but was also essentially constant as $\mathrm{C}_{\mathrm{a}}$ varied between 300 and $700 \mathrm{ppm}$, the range of concern regarding the future rise in atmospheric $\mathrm{CO}_{2}$. For all three species doubling of $\mathrm{CO}_{2}$ for growth did not change the $\mathrm{C}_{\mathrm{i}} / \mathrm{C}_{\mathrm{a}}$ ratio significantly. As expected, the ratio was much lower for the $C_{4}$ species (maize), reflecting low $C_{i}$ values, than for the $C_{3}$ species. The former fell in the 0.3 range (Fig, 2) whereas the latterfell in the 0.5 to 0.7 range (Fig, 1 and 3 ). Constant $C_{i} / C_{2}$ ratios would simplify the predictions and simulations of effects of elevated $\mathrm{CO}_{2}$ and environmental stresses on WUE.

Effects of pot size. It is known that pot experiments can be complicated by the downward regulation of photosynthesis under elevated $\mathrm{CO}_{2}$, which has been attributed to either a deficiency of mineral nutrients or a lack of sinks for photosynthetic assimilates because the space for root growth is limited. We encountered apparent downward regulation (indicated by a lower $A$ at a given $C_{i}$ ) when plants were grown in small pots ( 2.4 liters), especially at $2 \times \mathrm{CO}_{2}$. When large pots ( 7.4 or 7.7 liters) were used with good fertilization, $A$ reached the same high value under high $\mathrm{CO}_{2}$ concentrations regardless of the growth $\mathrm{CO}_{2}$ level, be it $360 \mathrm{ppm}$ or $720 \mathrm{ppm}$, indicating the absence of downward regulation caused by high $\mathrm{CO}_{2}$. Interestingly, although apparently downward regulated plants can show a substantial reduction in the rate of maximal photosynthesis, their $C_{j} / C_{a}$ 
ratio was similar to those of normal plants. This is additional evidence for the conservative nature of $\mathrm{C}_{\mathrm{i}} / \mathrm{C}_{\mathrm{a}}$.

It is not known whether the apparent downward regulation of photosynthesis is the result of nutrient deficiency or restricted rooting volume. That needs to be resolved in future studies.

Effects of $\mathrm{CO}_{2}$ on conductance for water vapor. For all three species, total conductance for water vapor ( $\mathrm{gW}$ ), which was mostly determined by leaf conductance because boundary layer conductance was very high in our stirred gas exchange chamber, declined with increases in $\mathrm{C}_{\mathrm{a}}$ as expected. The decline for cotton growing in pots of adequate size was not marked whereas the decline in maize was steeper (Fig. 4). The decline in soybean (Fig. 5) appeared to be between thet for ection and mize. Dopubling of the $\mathrm{CO}_{2}$ level for growing the plants, did not have any substantial effect on stomatal response to $\mathrm{CO}_{2}$ as indicated by the conductance data (Fig 4). On the other hand, plants growing in small pots usually had lower conductances (Fig 4 and S), which manifested as lower assimilation rates as already mentioned. The lower $g w$ for the plants in small pots apparently permitted the maintenance of similar $\mathrm{C}_{\mathrm{i}} / \mathrm{C}_{\mathrm{a}}$ ratio regardless of pot size.

Effects of PAR level on $C_{i}$ of plants grown at two levels of $\mathrm{CO}_{2}$. Assimilation was measured over a wide range of PAR and $C_{i}$ calculated. For cotton, $C_{i}$ remained constant over the PAR range of 500 to $2,100 \mu \mathrm{mol} \mathrm{m} \mathrm{m}^{-2} \mathrm{~s}^{-1}$, but rose somewhat as PAR decreased below $400 \mu \mathrm{mol} \mathrm{m}{ }^{-2} \mathrm{~s}^{-1}$ (Fig. 6). For maize, $C_{i}$ remained fairly constant over a PAR range of 600 to $2,100 \mu \mathrm{mol} \mathrm{m} \mathrm{m}^{-2} \mathrm{~s}^{-1}$ and rose substantially as PAR decreased below $400 \mu \mathrm{mol} \mathrm{m} \mathrm{m}^{-1}$ (Fig. 7). During those measurements $C_{a}$ remained constant, at $360 \mathrm{ppm}$. Hence, it is clear that $\mathrm{C}_{\mathrm{i}} / \mathrm{C}_{\mathrm{a}}$ ratio remained constant within the range of high to moderate PAR, but rose as PAR was reduced to low levels common for early mornings and very late afternoons. More importantly, doubling the growth $\mathrm{CO}_{2}$ level had no effect on the response of $\mathrm{C}_{i}$ (hence $\mathrm{C}_{\mathrm{j}} / \mathrm{C}_{\mathrm{a}}$ ) to variations in PAR (Fig. 6 and 7 ), Effects of other variables, particularly temperanre and leaf age (after reaching full size but before senescence) were also negligible or very small (data not shown).

\section{Efrects of Elevated $\mathrm{CO}_{2}$ on Growth and Biomass WUE}

Doubling of $\mathrm{CO}_{2}$ in the growth chamber increased the biomass and improved the efficiency of water use of cotton, soybean, bean, and maize. The shoot dry weight of the 
plant at different times as determined by sequeptial harvests was plotted against the cumultive amount of water used as determined by weighing the pots at each harvest. Biomass WUE (biomass produced/cumulative transpiration, abbreviated as $\mathrm{WUE}_{\mathrm{mt}}$ ) was calculated as the slope of the plots, which were linear. Examples of the data are given as Fig. 8 and 9 , for cotton. The increase in WUEmt was $84 \%$ and $93 \%$, respectively. With soybean, another $\mathrm{C}_{3}$ species, similar improvement in $W U E_{m t}$ was observed. As expected, the improvement in $W_{U E} E_{m t}$ for maize, a $C_{4}$ plant, was much less marked, only about 25\%. Elevated $\mathrm{CO}_{2}$ is known to increase the total leaf area of $\mathrm{C}_{3}$ plants. Some studies attributed this to increases in the number of leaves but no real increase in leaf size. We found that size of the leaves on each node of cotton was increased substantially under $2 x$ $\mathrm{CO}_{2}$ (Fig 10) In anddifion, after 30 in 40 d of growth, there was one mone leat on the main stam under $2 \times \mathrm{CO}_{2}$, as well :as,mone branching. Size of maize leaves was also enhanced under $2 \mathrm{xOP}_{2}$ and the number of leaves at the sampling time.inereased by one (Fig. 10), which indicates the plant under high $\mathrm{CO}_{2}$ was slightly more advanced in ontogeny.

Cotton plants spaced apart were compared with those spaced closoly with their canopies overlapping. The response in biomass production to a doubling of $\mathrm{CO}_{2}$ was found to be reduced substantially by the close spacing. This finding is in accordance with a theoretical prediction (Hsiao, 1993) based the first order kinetics of radiation interception by growing but incomplete canopies, and points to an important but ustally unappreciated factor causing variations in the biomass response to $\mathrm{CO}_{2}$.

\section{Testing of Theoretical WUE Framework with Chamber Grown Plants}

The constancy of $\mathrm{C}_{\mathrm{i}} / \mathrm{C}_{\mathrm{a}}$ ratio under most conditions regardless of the level of $\mathrm{CO}_{2}$ under which the plants are grown is very encouraging. It should simply the task of using the theoretical framework of Hsiao (1993) to predict changes in WUE brought about by global change, whether due to increases in atmospheric $\mathrm{CO}_{2}$ or to environmental stresses. At the risk of pointing out the obvious, we calculated photosynthetic WUE using Eq. 9 of Hsiao for a cotton leaf over the range of $C_{a}$ used to obtain the $A$ vs. $C_{j}$ curve for that leaf and plotted the results against photosynthetic WUE calculated from the measured assimilation and transpiration rate (Fig. 11). The comparison shows near coincidence (1:1 line) between the predicted and observed WUE, with the deviation of individual data points accounted for by experimental inaccuracies and slight oscillations in the values of $\mathrm{C}_{\mathrm{i}} / \mathrm{C}_{\mathrm{a}}$. The outcome is obvious because the calculation of the gas exchange data involves exactly the same assumptions and equations as those used to derive Eq. 9 of Hsiao (1993). That 
emphasizes the fundamental nanure of the equation, which may be taken as a first principle of water use efficiency as long as it is applied to individual leaves. Complications may arise, however, when scaling up to the whole plant and to canopies made up of many plants.

To test how far the simplicity of the framework equation may go, we applied it to the whole plant level by evaluated the experimental biomass WUE data obtained on cotton (Fig. 8 and 9). Leaf temperature was measured with fine wire thermocouples, and along with the air humidity record, was used to calculate the parameter $\Delta W$ (difference in water vapor concentration between the leaf interior and the bulk air) required by the framework. From the ratio of air $\mathrm{CO}_{2}$ concentration and of $\Delta \mathrm{W}$ for the two different $\mathrm{CO}_{2}$ environments, the increase in photosynthetic WUE brought about by growing the plants in 720 . ppm compared to $360 \mathrm{ppm} \mathrm{CO}_{2}$ was predicted to be $92 \%$. This corresponds to the measured mean increase in WUEmt of $89 \%$ (84\% for Fig. 8, and 93\%. for Fig. 9). The agreement is remarkably good when considering random errors, the complications of scaling up from single leaves to the whole plant, and night time transpiration and respiration. It is possible that many of the complicating factors had opposite effects and hence canceled out each other over time. Two other experiments with cotton gave equally close predictions, within 5\% of the measured change in WUE. In addition, we conducted more complicated tests of the framework by growing plants under one level of $\mathrm{CO}_{2}$ and humidity for 2 weeks or longer and then changed the condition to a different $\mathrm{CO}_{2}$ and humidity. There the framework also predicted well the change in WUEmt, usually within $10 \%$ of the measured values. These exciting results are being written up for publication.

\section{Field Experiments on Various Aspects of WUE}

Water use efficiency for biomass production. Two experiments were conducted on maize in the fjeld, one in 1994 and one in 1995. One half of a large field (about 5 hectares) was well watered and served as the control and the other half was water stressed by withholding irrigation at different times after canopy establishment and had to rely on only the water stored in the soil. In 1994 water stress developed late in the season and only became substantial near the time of harvest. In 1995 water stress became relatively severe in midseason and was relieved by irrigation, and became severe again near the time of harvest. Associated with the midseason water stress was some nitrogen deficiency, due to inability of the plants to take up sufficient nitrogen from the dried out top soil where nitrogen fertilizer was applied. The water stress late in 1995 was severe enough to accelerate senescence of the leaves, reducing leaf area duration and grain yield. Biomass 
consumptive water use efficiency (WUE $E_{m e}$ ), the ratio of dry matter produced to the amount of water eyapotranspired, was determined by soil water balance and sequential harvests. When normalized for variations in the evaporative demand due to weather, WUEme, determined from the slope of plots of dry matter vs. water evapotranspired (Fig. 12), was similar for the dry treatment and the control, with a tendency of the dry treatments to be lower. This is not surprising as it is consistent with the WUE framework for single leaves if $\mathrm{C}_{\mathrm{i}} / \mathrm{C}_{\mathrm{a}}$ is not altered significantly by water stress (Hsiao, 1993).

Ear respiration. In the same experiments, respiration of maize ears (the fruiting body) was measured to determine their negative contribution to the carbon balance (and hence WUE) of the crop. Respiration rate per gram of ear dry weight was very high at the time of ear emergence, due to the dominance of fas grouing bispe with high growth respiration, but declined rapidly with ear age (Fig. 13) as the proportion of growing, tissue declined and mature tissue increased. The rates for the dry treatment tended to be lower than the control, probably due to slower growth On a per ear basis, respiration rate increased with ear age due to the rapid gain in ear mass. Respiration constituted a substantial carbon drain during the grain filling. When expressed on a basis of land area (Fig. 13), respiration was equivalent to about $20 \%$ of midday net canopy photosynthesis at mid grain filling stage, and to about $30 \%$ to $40 \%$ of midday net canopy photosynthesis at late grain filling stage.

Canopy photosynthesis and eyapotranspiration. During the two field seasons, daily time course of maize canopy photosynthesis and evapotranspiration were measured with the Bowen ratio/energy balance technique. An example of the data (for $5 \mathrm{~min}$ intervals) for the dry treatment and the control on the same date is given in Fig. 14, showing the daily pattern of ET (in terms of negative latent heat flux $\lambda \mathrm{E}$ ), $\mathrm{CO}_{2}$ assimilation, PAR, air and canopy temperature, and the ratio of A to ET (, canopy photosynthetic WUE). During that late growth stage (Sept. 12, 1995), leaf area had declined substantially in the dry treatment compared to the control and intercepted less PAR. Dry treatment also had a substantially lower leaf water potential and less nitrogen in the leaves. As the consequence, ET was less for the dry treatment compared to the control and so was canopy photosynthesis. The AVET ratio was generally also lower for the dry treatment, indicating a lower WUE. WUE was the highest in early moming because of low temperanure and high relative humidity, and lowest in the aftemoon because of high temperature and low relative humidity. More extensive data of similar nature were obtained on maize in 1996, and on cotton in 1997. Because of the extensiveness of the data sets, analysis of the results is still ongoing. 
Micrometeorological data on profiles of temperature, $\mathrm{CO}_{2}$, and water vapor.. To define better the conditions experienced by the cmp.canopies and for the validation of the higher order closure models, we have obtained 30 min mean profiles of wind, temperature, $\mathrm{CO}_{2}$ concentration, and humidity above and within maize and cotton canopies on a number of selected days. Examples of the data for maize are given in Fig. 15. The results show that on days of strong wind, $\mathrm{CO}_{2}$ concentrations within and above the canopy was uniform and close to ambient. In contrast, $\mathrm{CO}_{2}$ concentrations were highly variable around the canopy on calm days, as high as $>420 \mathrm{ppm}$ in the morning, dropping to lows of $320 \mathrm{ppm}$ early in the afternoon. The impact of these variation on canopy photosynthesis and WUE havo not been taken into account in most of the current studies.

\section{Testing of Theoretical Wur Framework in Crop Fields}

The natural variation in $\mathrm{CO}_{2}$ concentration and hurnidity with time in the field on calm days made it possible to test the WUE framewodk of Hisiao (1993). Canopy photosynthetic WUE was calculated at 5 min intervals as the ratio of measured assimilation and evapotranspiration (A/E, see Fig. 14). Taking noon time WUE as the reference point, WUE for the other times of the day was predicted using Hisiao's framework, utilizing the measured values of air humidity and $\mathrm{CO}_{2}$ concentration, and canopy temperature. In the limited analyses carried out so far, the predicted diurnal trend in WUE matched well the measured trend in WUE. This exciting result is surprising and unexpected, since strictly speaking, the framework was applicable only to single leaves and scaling up should introduce considerable complexity, especially in the regl-world situation of the field in comparison to the controlled environment chambers. The bulk of the remaining data collected over the last two seasons are still been analyzed, to verify this potentially highly important finding.

\section{Model Development}

Early in this project, in anticipation of the need to scale up mechanistically from the single leal to the canopy level and beyond, we worked on developing and impoving models for canopy function. Model development proceeded among several avenues. The first was the development of a coupled stomatal control and photosynthesis model. The second was the preliminary investigation of the implications of our hypothesis that the ratio $\mathrm{Ci} / \mathrm{Ca}$ is constant on physiological responses. Lastly, the third was the modification of an existing higher-order closure model to describe the canopy-atmosphere exchange process.

The empirical stomatal control theory of Ball-Berry (Collatz ot al., 1991) was coupled analytically and numerically with the von Caemmerer-Farquhar photosynthesis 
model. The coupling led to a cubic solution, which had to be iterated with a quartic (4thorder polynomial) energy budget equation, to arrive at a simultaneouss solution for leaf conductance, photosynthesis, leaf temperature, and leaf energy budget. This model was then used to investigate transient features of plant response to large, repeated turbulent features called 'coherent structures'. An interesting result of this simulation was.that $\mathrm{C}_{\mathrm{i}}$ was predicted to respond quickly to atmospheric turbulence.

The hypothesis that a constant $\mathrm{C}_{\mathrm{i}} / \mathrm{C}_{\mathrm{a}}$ ratio is exhibited by plants has certain implications when combined with equations describing stomatal conductance and photosynthesis. When the assumption of a constant ratio is incorporated and combined with the von Caemmerer- Farquhar photosynthetic equation, a new equation results which shows that stomtal conductance decreases witb increases in ambient $\mathrm{CO}_{2}$ eanceratuation, as is observed (e.go, Fig. 4). If the Ball-Bfrry stomal conductance equation is used in combination with the von Caemmerer-Farquhar photosynthesis equation, $C_{2} / C_{a}$ ratio is not strictly constant, but can be shown to vary only slightly under certain envirommental conditions. These results provide interesting insights and their ramification is being explored.

A layered canopy model using higher-order closure (Paw $U$ and Meyers, 1989) was further developed for describing the coupled energy budget and photosynthetic flux exchange between the canopy and the atmosphere. This model has 10 layers of plant canopy above one layer of soil, with another 30 layers of atmosphere above the canppy. Each canopy layer consists of 10 leaf classes, 9 representing sunlit leaves of different angles, and one shaded leaf class. For each leaf class, a full energy budget is solved, and the $\mathrm{CO}_{2}$ flux is calculated. Inter layer exchange is described by higher-order closure principles, based on the equations of fluid motion and principles of mass and energy conservation. To provide the radiation field needed for energy budget calculations, the two-stream model of Norman (1979) was employed. Plant physiology is included by one of the two user-selected methods; the combined Ball-Berny stomatal conductance and von Caemmerer-Farquhar photosynthesis model, or a multiplicative model including the effects of leaf temperature, vapor pressure deficit, and PAR.

The higher-order closure model was run for differing values of air temperature and $\mathrm{CO}_{2}$ concentration, to investigate how the canopy may respond to climate change in terms of $\mathrm{CO}_{2}$ flux, canopy photosynthetic WUE (A/E), and canopy resistances. Not surprisingly, the mean $\mathrm{CO}_{2}$ concentration is strongly dependent on physiolagy modeling. As expected, the canopy resistance rises with $\mathrm{CO}_{2}$ concentration for the Ball- Berry/von Caemmerer-Farquhar model, but is unrealistically constant in the multiplicative model. 
This causes the actual $\mathrm{CO}_{2}$ fluxes to increase less for the former than for the latter model. Therefore, the increase in AE is greater for the multiplicative model than for the Ball and Berry model. The experimental data collected are still to be used to test the different models.

The overall results (Paw $U$ et al, 1996) show that carbon assimilation rates for different $\mathrm{CO}_{2}$ levels are very different, depending on the difference in canopy-atmosphere model and in physiology model. Thus, it is critical that these models be tested against the experimental data already collected in the field.

\section{References Cited}

Collatz, G.J., Rivet, C., Ball, J.T., and Berry, LA 1991. Physiolagieal and envirommental.regulation of stomatal condweme, photosynthesie and tanspiratipn: a model that includes a laminar boundary layer. Agric. For. Meteorol, 54:107-136.

Hsiao, T. C. 1993. Effects, of drought and elevated $\mathrm{CO}_{2}$ on plan water use efficiency and productivity. In: M. B. Jackson and C. R. Black (eds.) Interacting Stresses on Plants in a Changing Climate, NATO ASI series. Vol. I 16. Springer-Verlag, Berlin pp. 435-465.

Norman, J.M., 1979. Modelling the complete crop canopy- In: Modification of the Aerial Environment of Crops, ASAE Mongraph, ASAE, St. Joseph, MI.pp. 249-277.

Paw U, K. T, and L. T. Meyers. 1989. Investigations with a higher-order canopy turbulence model into mean source-sink levels and bulk canopy resistances. Agric. For. Meteorol.47:259-272.

Paw U, K. T., H.-B. Su, D. Charlevoix, T.C, Hsiao. 1996. Testing of an advanced plant physiology leaf model linked with a plant atmosphere higher-order closure turbulance model for response to elevated $\mathrm{CO} 2$ concentrations. 22nd Conference on Agricultural and Forest Meteorology, Atlanta, Georgia. American Meteorological Society, Boston,.

\section{Publications Supported by the Grant:}

Hsiao, T. C. 1994. Crop productivity and the future world of elevated $\mathrm{CO}_{2}$ and changed climate. In:: M. Borin and M. Sattin (eds.) Proc. Third Cong. European Soc. Agron., Abano-Padova. ESA, Colmar Cedex, France. pp. 6-17.

Paw U, K. T., Su, H.-B., Charlevoix, D., and Hsiao, T. C. 1996. Testing of an advanced plant physiology leaf model linked with a plant-atmosphere higher-order closure turbulence model for response to elevated $\mathrm{CO}_{2}$ concentrations. 22nd Conf. 
Agric. Forest Meteorol, Atianta, Georgia, Am. Meteorol. Soc/, Boston, MA. Pp. J58-59.

Su, H.-B., Paw U, K. T., and Shaw, R. H. 1996. Development of a coupled leaf and canopy model for the simulation of plant-atmosphere interaction. J. Appl. Meterol. In press.

Steduto, P. and T. C. Hsiao. 1998. Maize canopies under two soil water regimes. I. Diurnal patterns of energy balance, carbon dioxide flux, and canopy conductance. Agric. For. Meteorol. 89:169-184.

Steduto, P. and T. C. Hsiao. 1998. Maize canopies under two soil water regimes. II. Seasonal trends of evapotranspiration, carbon dioxide assimilation and canopy conductance, and as related to leaf area index. Agric. For. Metearol. 89:185-200.

Steduto, P. and T. C. Hsian. 1998. Maize canopies under two soil water regimes. II Variation in conpling with the anmosphere and the role of leaf area index. Agric. For. Meteorol 89:201-213.

Steduto, P. and T. C. Hsiao. 1998. Maize canopies nnder two soil water regimes. IV. Validity of Bowen ratio-energy balance technique for measuring water vapor and carbon dioxide fluxes at 5-minute intervals. Agric. For. Meteorol. 89:215-228.

Hsiao, T. C. and R. Jackson. 1998. Interactive effects of water stress and elevated $\mathrm{CO}_{2}$ on growth, plotosynthesis, and water use efficiency, In: Y. Luo and H. A. Mooney (eds.) Carbon Dioxide and Environmental Stress. AcademicPress. In press. 


\section{Cotton}
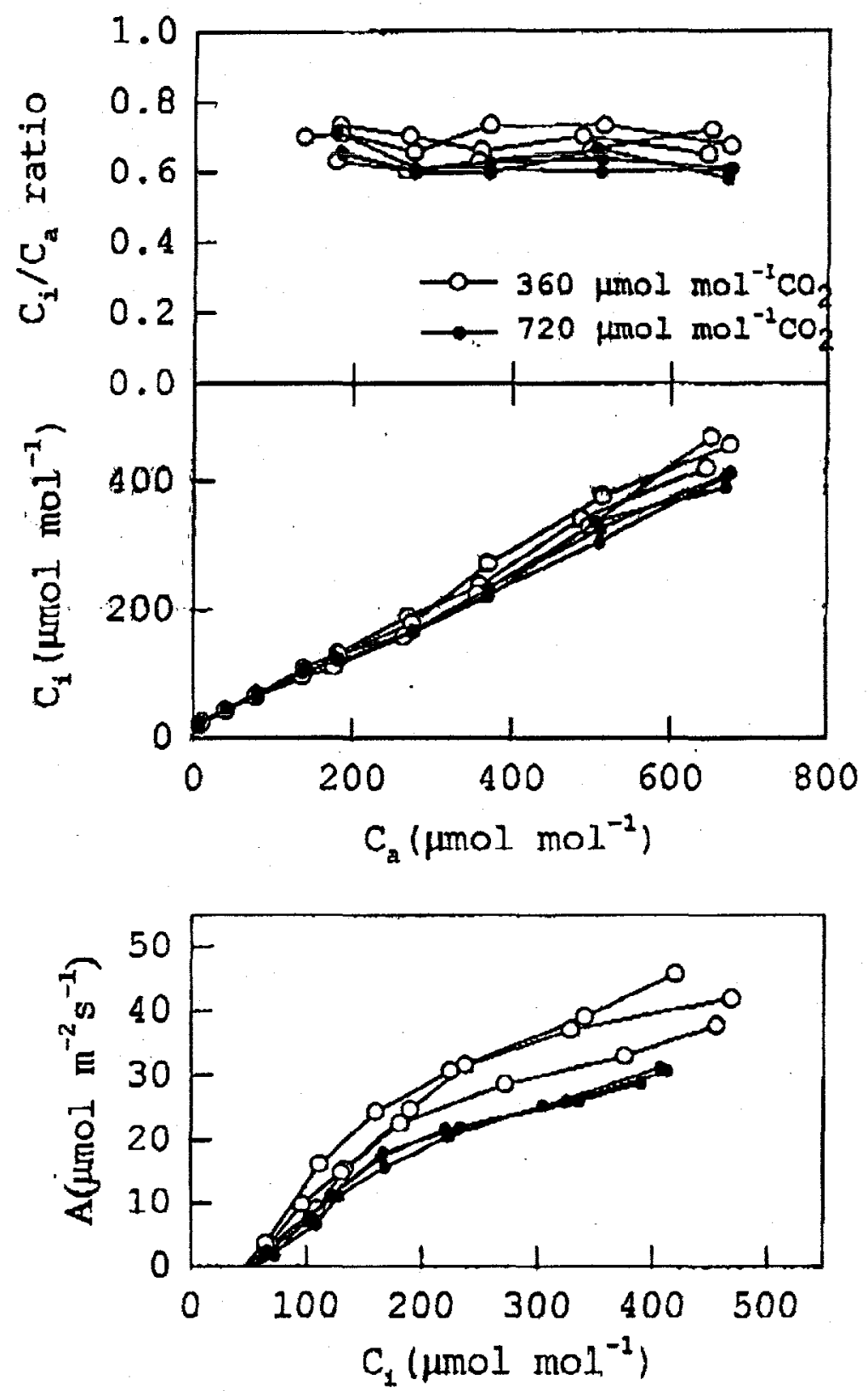

Fig. 1. Leaf photosynthesis rate (A) vs. intemal $\mathrm{CO}_{2}$ concentration $(\mathrm{Ci}), \mathrm{Ci}$ vs. $\mathrm{Ca}$ and $\mathrm{Ci} / \mathrm{Ca}$ ratio vs. $\mathrm{Ca}$, for recently matured and exposed cotton leaves grown at either $360 \mathrm{umol}^{\mathrm{mol}} \mathrm{m}^{-1}$ $(\mathrm{ppm}, \mathrm{v} / \mathrm{v})$ or $720 \mathrm{\mu mol} \mathrm{mol}^{-1} \mathrm{CO}_{2}$. Measurements were made in a steady state gas exchange chamber at $28^{\circ} \mathrm{C}$ and 1.5 to $1.8 \mathrm{kPa}$ vapor pressure difference between leaf interior and the air (DW) under $1,400 \mu \mathrm{mol} \mathrm{m}^{\prime 2} \mathrm{~s}^{-1}$ of PAR. Variation in Ci was achieved by varying Ca. Each line represents one leaf of a different plant. 
Corn
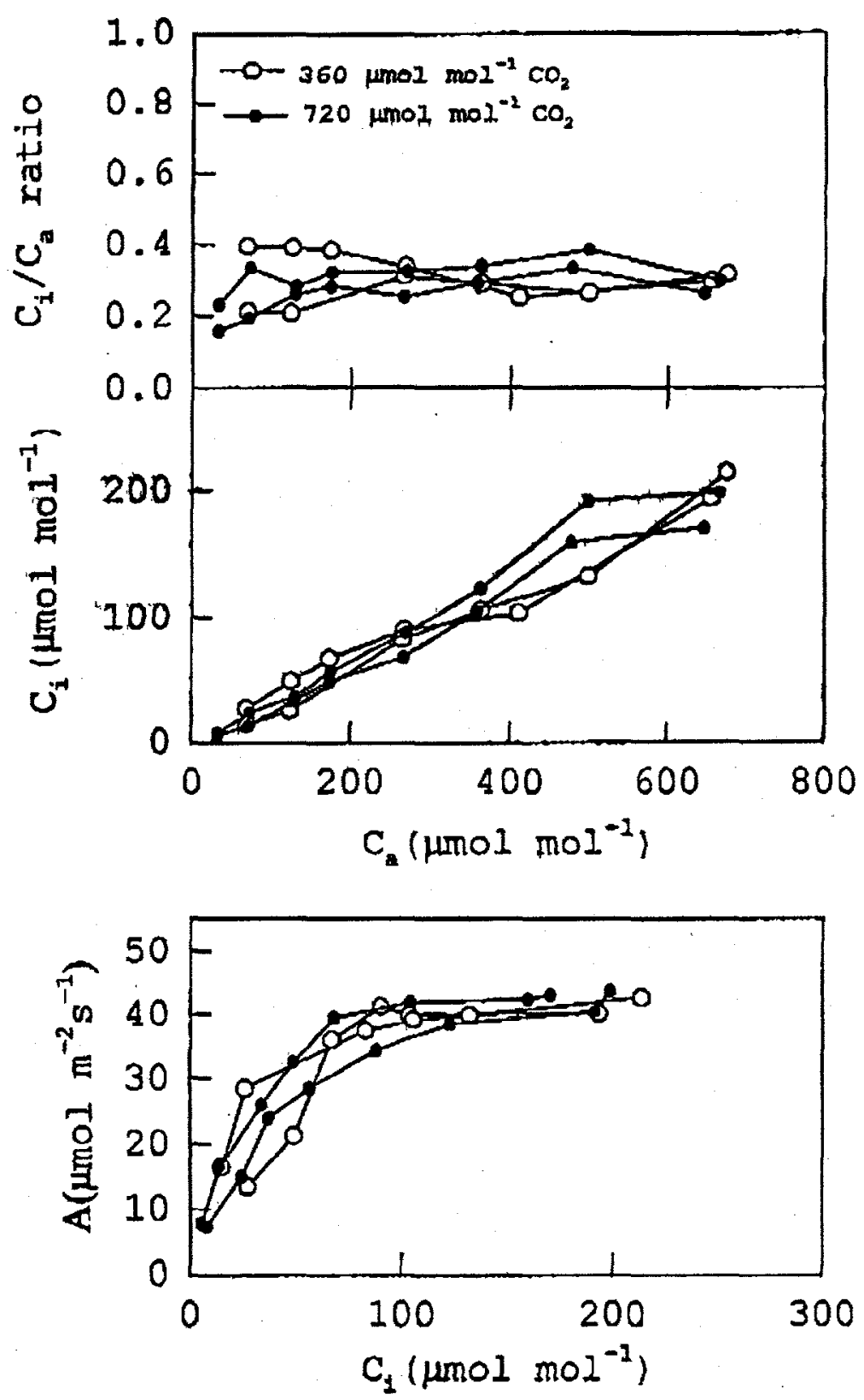

Fig. 2. Leaf photosynthesis rate (A) vs. internal $\mathrm{CO} 2$ concentration $(\mathrm{Ci}), \mathrm{Ci}$ vs. $\mathrm{Ca}$, and $\mathrm{Ci} / \mathrm{Ca}$ ratio vs. Ca, for recently matured and exposed maize leaves grown or either $360 \mathrm{~mol} \mathrm{~mol}^{-1}$ (ppm, v/v) or $720 \mu \mathrm{mol} \mathrm{mol}^{-1} \mathrm{CO2}$. Measurements methods and conditions were as given under Fig. 1. Each line represents one leaf of a different plant. 

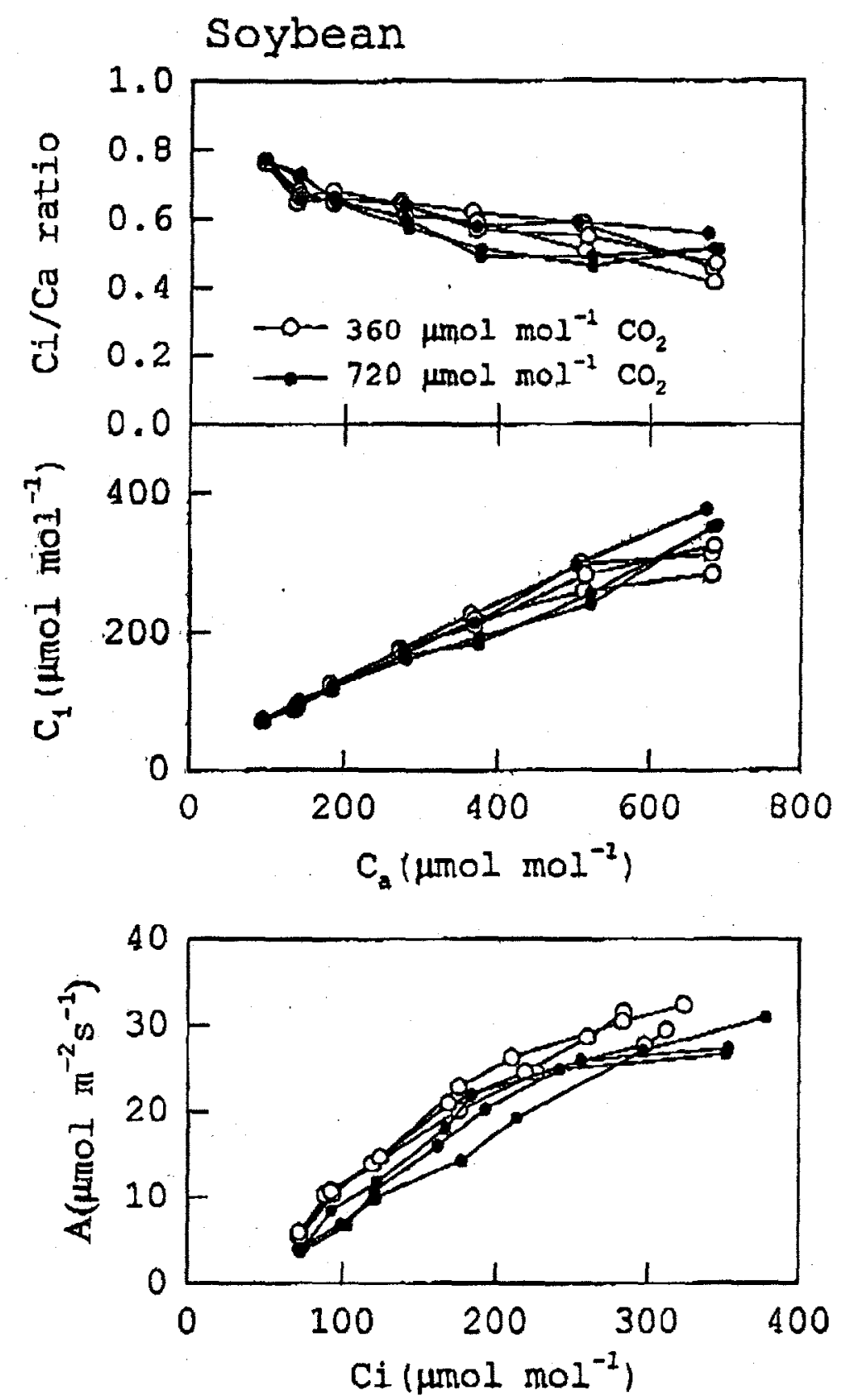

Fig. 3. Leaf photosynthesis rate (A) vs. intemal $\mathrm{CO} 2$ concentration ( $\mathrm{Ci}$ ), $\mathrm{Ci}$ vs, $\mathrm{Ca}$ (air $\mathrm{CO} 2$ concentration), and $\mathrm{Cl} / \mathrm{Ca}$ ratio vs. $\mathrm{Ca}$, for recently matured and exposed soybean leaves grown at either $360 \mu \mathrm{mol} \mathrm{mol} \mathrm{l}^{-1}(\mathrm{ppm}, \mathrm{v} / \mathrm{v})$ or $720 \mu \mathrm{mol} \mathrm{mol}^{-1} \mathrm{CO2}$. Measurements meathods and conditions were as given under Fig. 1. Each line represents one leaf of a different plant. 


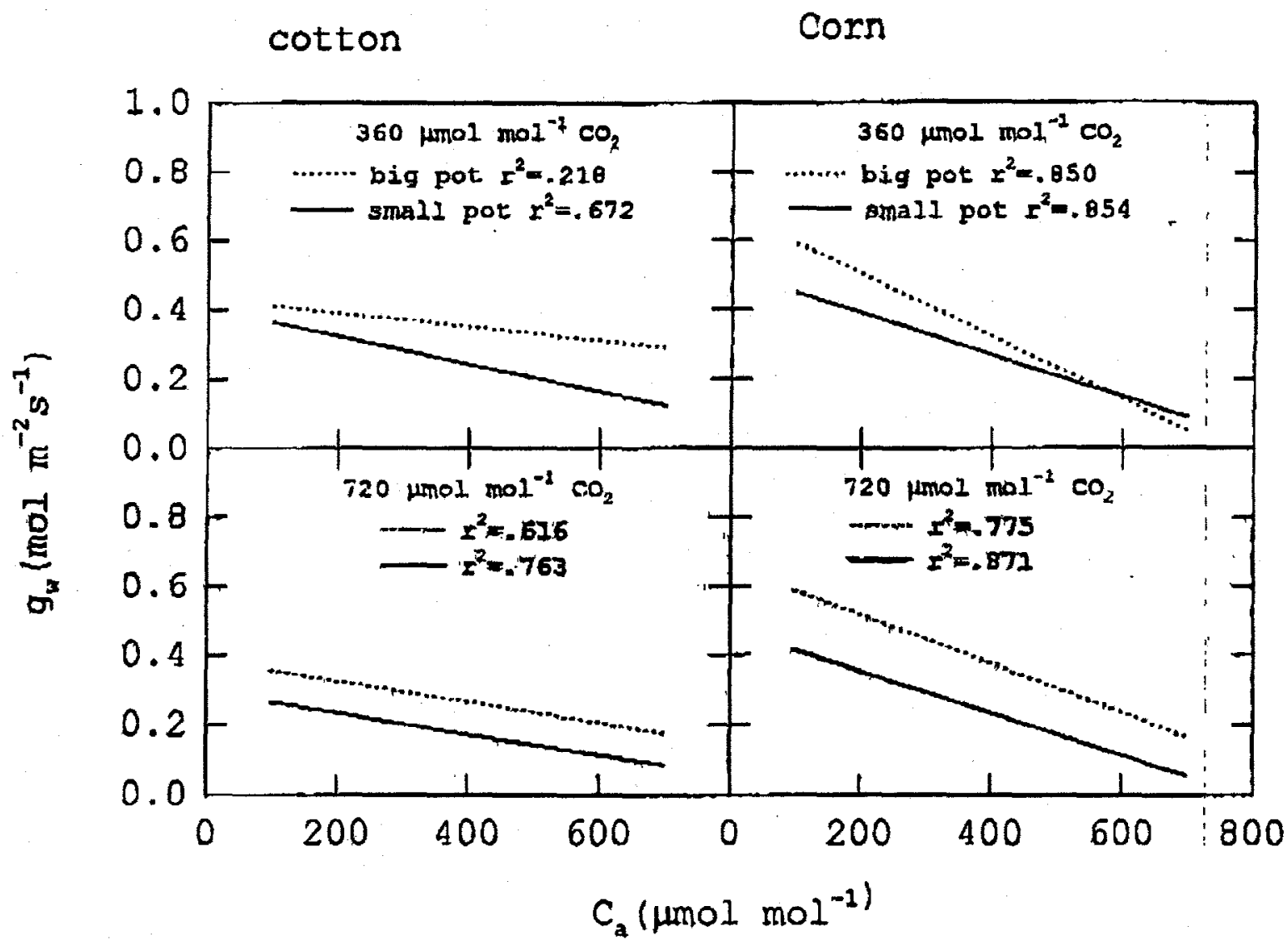

Fig. 4. Total conductance for water vapor $\left(\mathrm{g}_{w}\right)$ in relation to air $\mathrm{CO} 2$ concentration ( $\mathrm{Ca}$ ) for leaves of cotton and corn grown in either small or big pots at either 360 or $720 \mu \mathrm{mol} \mathrm{mol}{ }^{-1}(\mathrm{ppm}, \mathrm{v} / \mathrm{v})$ of $\mathrm{CO} 2$. Regressions were based on data from at least 4 leaves, each from a different plant. Boundary layer conductance was very large and constant so changes in $\mathrm{g}_{w}$ was the result of changes in leaf epidermal (mostly stomatal) conductance. 


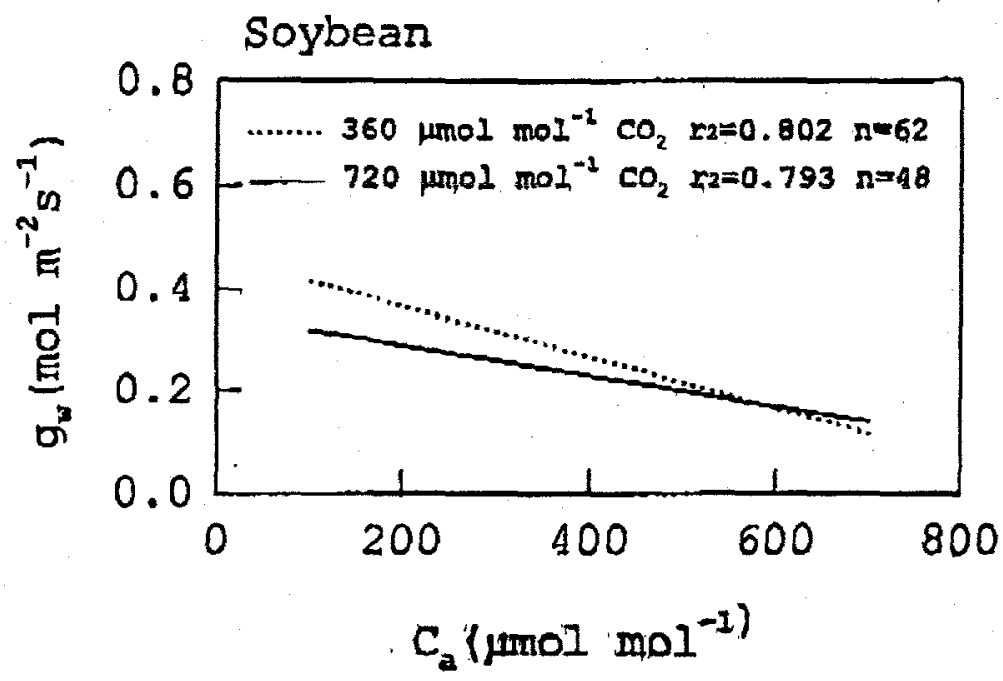

Fig. 5. Total conductance for water vapor $\left(\mathrm{g}_{w}\right)$ in relation to air $\mathrm{CO} 2$ concentration $(\mathrm{Ca})$ for leaves of soybean grown in either small or big pots at either 360 or $720 \mu \mathrm{mol} \mathrm{mol}{ }^{-1}(\mathrm{ppm}$, $\mathrm{v} / \mathrm{v})$ of $\mathrm{CO} 2$. 


\section{Cotton}

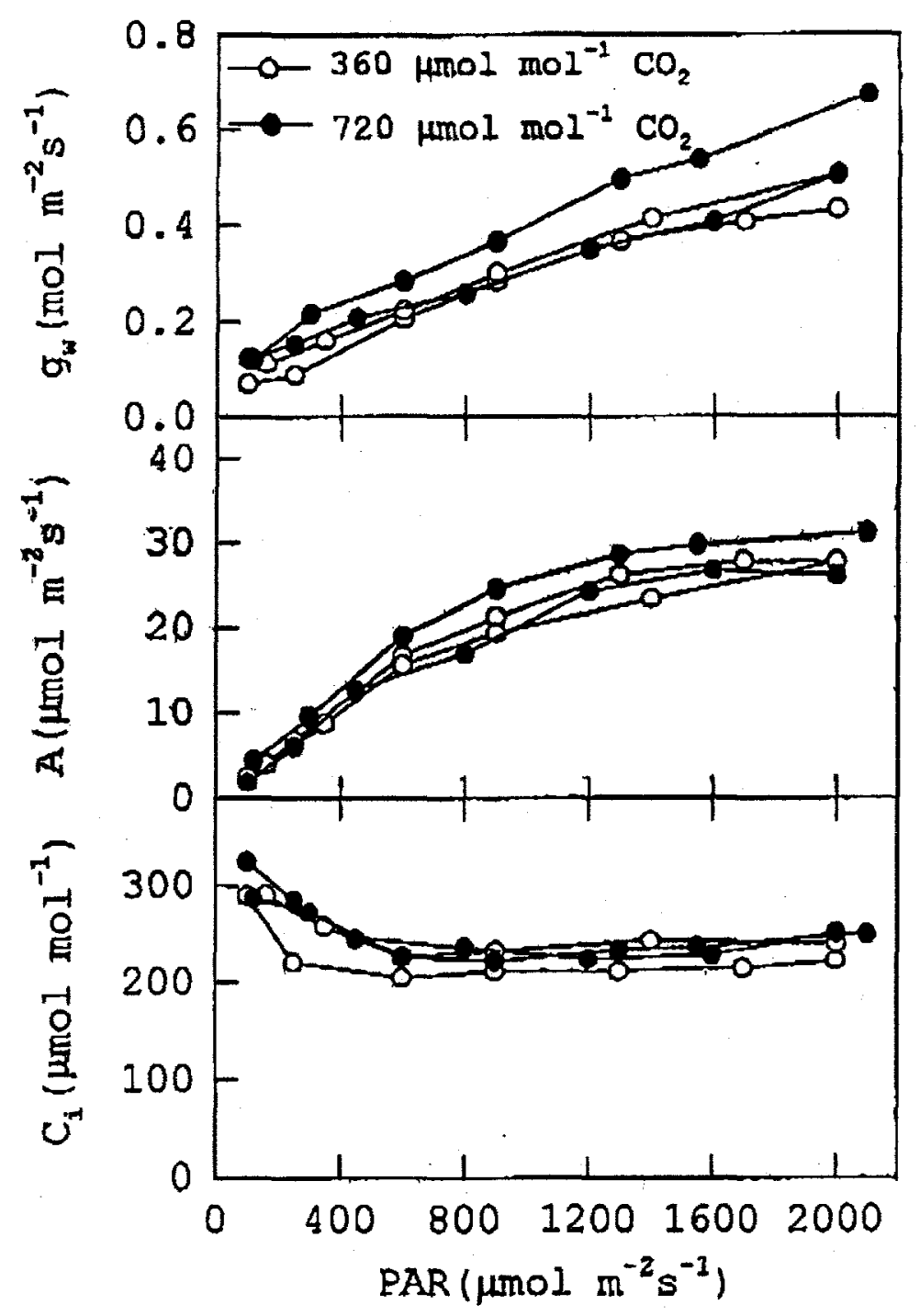

Fig. 6. Effects of incident PAR on $\mathrm{g}_{w}, \mathrm{~A}$, and $\mathrm{Ci}$ of leaves of cotton grown at either 360 or 720 $\mu \mathrm{mol} \mathrm{mol}{ }^{-1}(\mathrm{ppm}, \mathrm{v} / \mathrm{v})$ of $\mathrm{CO}$. Each line represents one leaf of a different plant. 


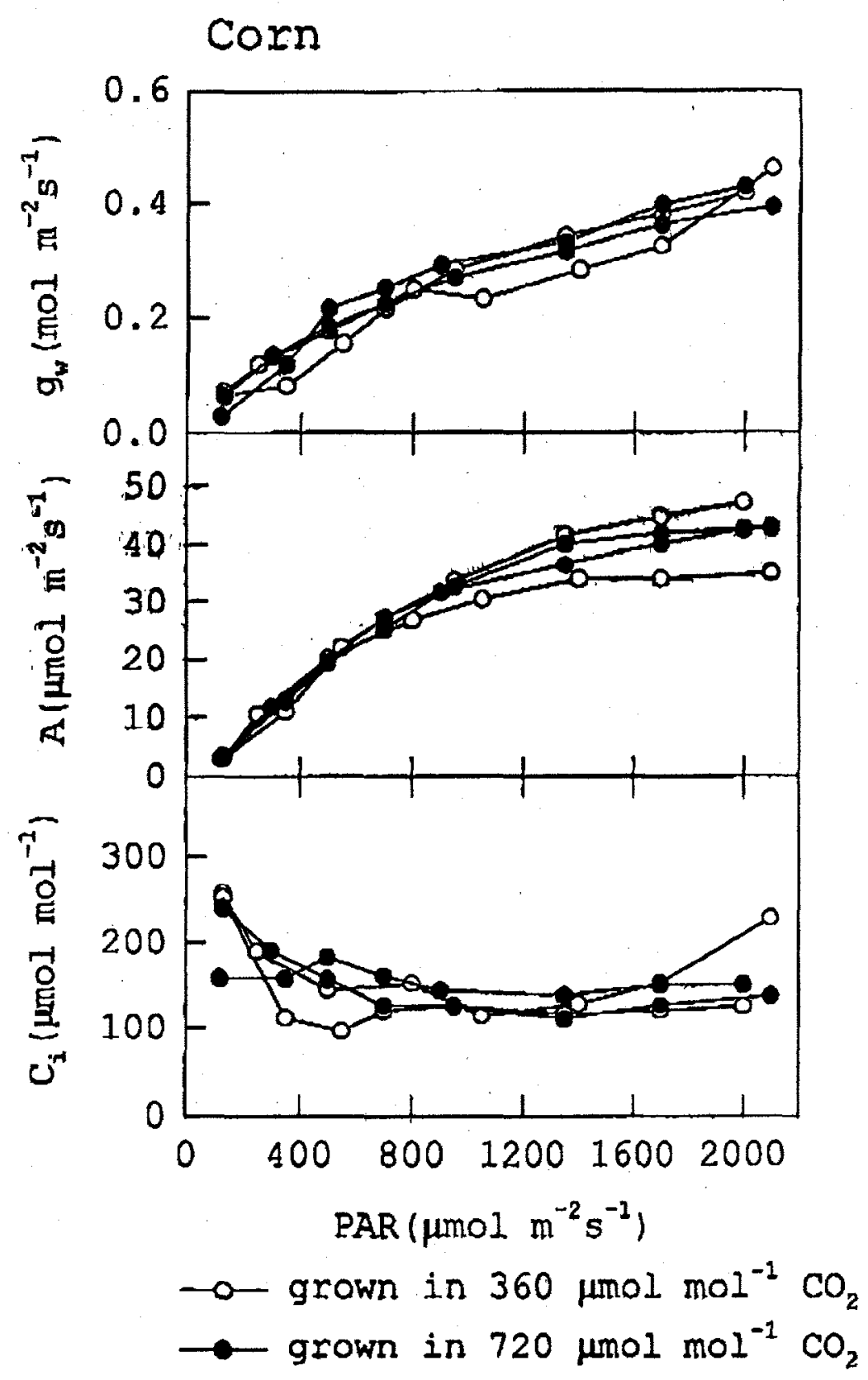

Fig, 7. Effects of incident PAR on $\mathrm{B}_{w}, \mathrm{~A}$, and $\mathrm{Ci}$ of leaves of maize grown at either 360 or 720 $\mu \mathrm{mol} \mathrm{mol}^{-1}(\mathrm{ppm}, \mathrm{v} / \mathrm{v})$ of $\mathrm{CO} 2$. Each line represents one leaf of a different plant. 

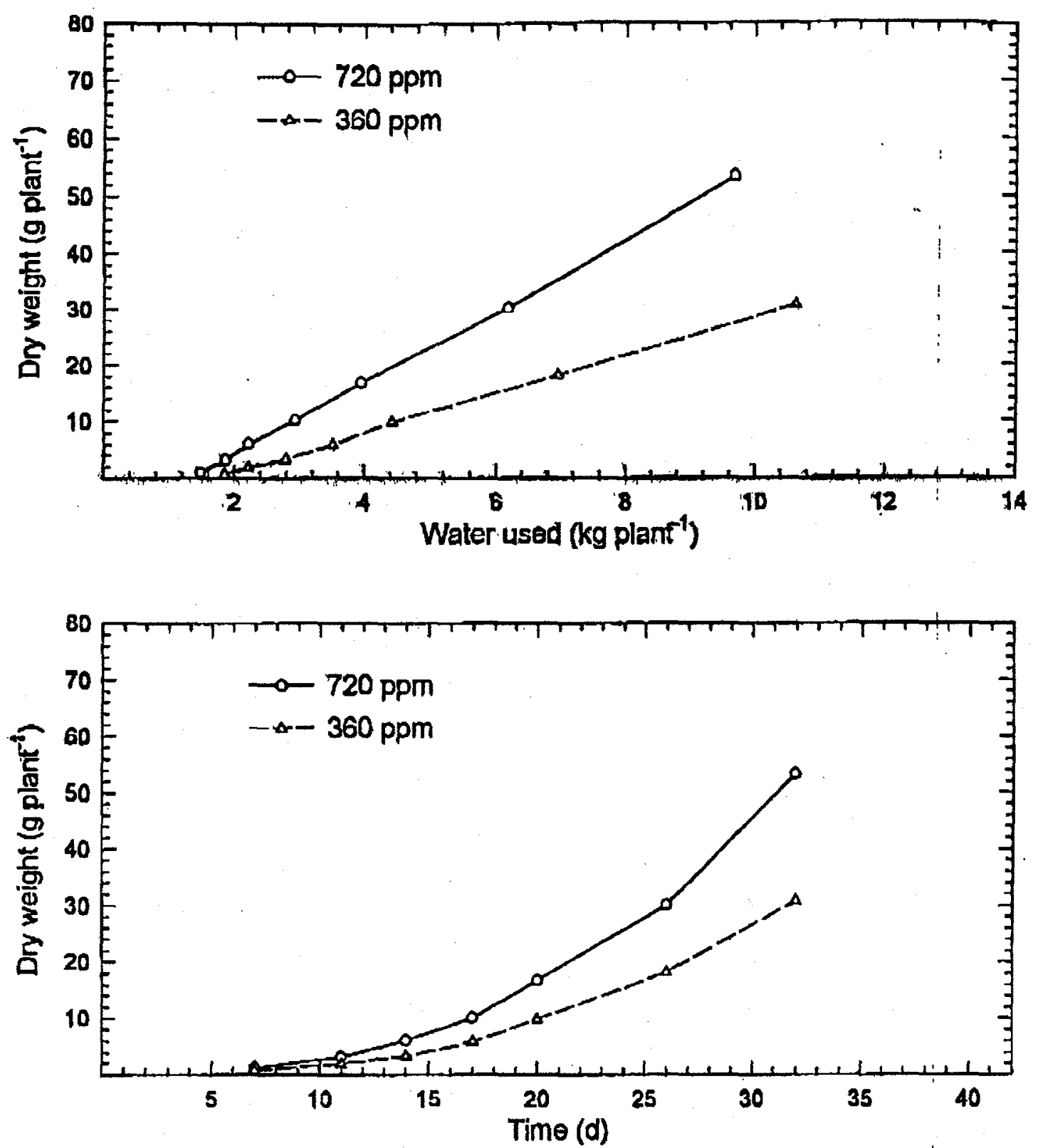

Fig. 8. Shoot dry matter of cotton planted on $8 / 27 / 1995$ and growing in growth chamber at either 360 or $720 \mathrm{ppm} \mathrm{CO} 2$ as a function of cumulative transpiration and a function of time; Dry matter was obtained by sequential harvest of 4 plants each. Transpiration was determined by ladding known amounts of irrigation and weighing soil water content. Temperature was $27 / 20^{\circ} \mathrm{C}$ and relative humidity was $40 / 80 \%$, for day (14h) and night periods. Transition between day and night was gradual and took $1 \mathrm{~h}$ each. PAR was $770 \mu \mathrm{mol} \mathrm{m} \mathrm{m}^{-2} \mathrm{~s}^{-1}$ and was increased and reduced in serval steps during the transition. Biomass water use efficiency (WUEmt), calculated as the slope (top figure) by linear regression $\left(r^{2}=0.999\right)$, was 3.45 and $6.35 \mathrm{~g} \mathrm{~kg}^{-1}$, for the 360 and 720 ppm plants. 

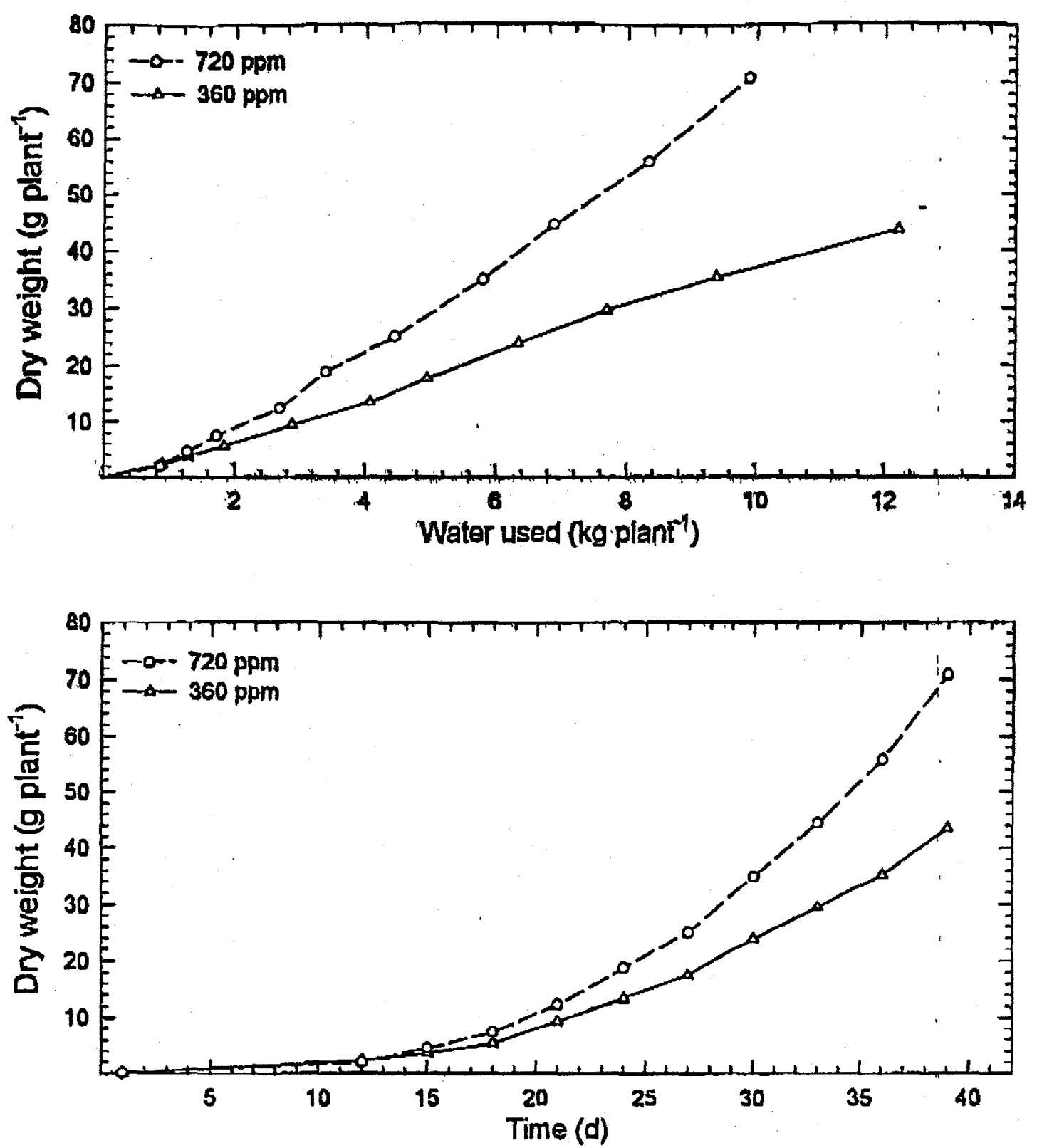

Fig, 9. Shoot dry matter of cotton planted on 12/14/1995 and growing in growth chamber at either $360 \mathrm{ppm}$ or $720 \mathrm{ppm} \mathrm{CO2}$ as a function of cumulative transpiration and as a function of time. Same conditions and methods as for Fig. 8, except that relative humidity was $45 \%$ during the day period. WUEmt was calculated $\left(r^{2}=0.99\right)$ to be 3.76 and $7.25 \mathrm{~g} \mathrm{~kg}^{-1}$, respectively, for the 360 ppm and 720 ppm plants. 


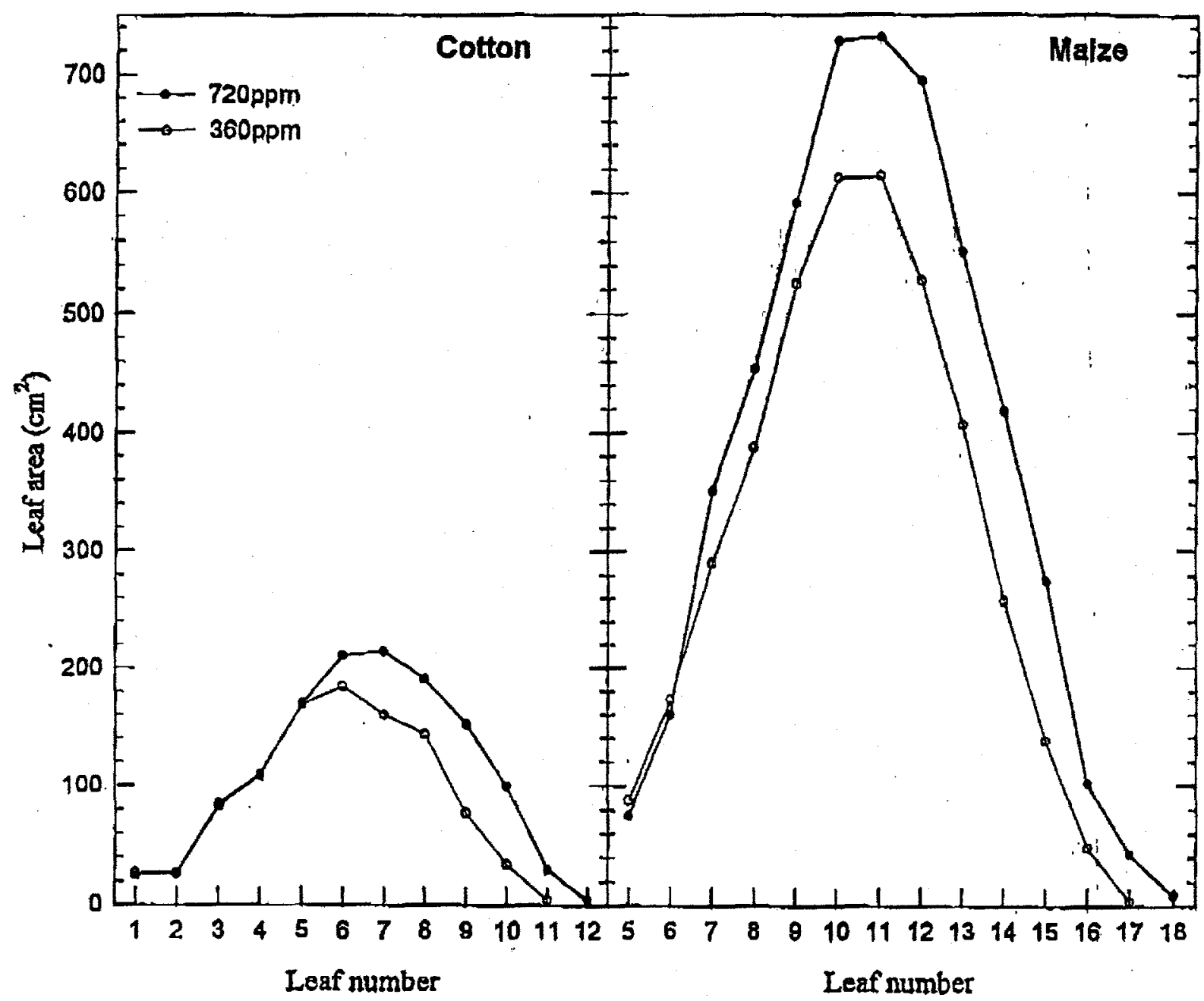

Fig. 20. Areas of individual leaves of cotton and maize grown in growth chamber at either $360 \mathrm{ppm}$ or $720 \mathrm{ppm} \mathrm{CO}$. Leaf number was in the order of emergence.

Conditions were the same as Fig. 8 


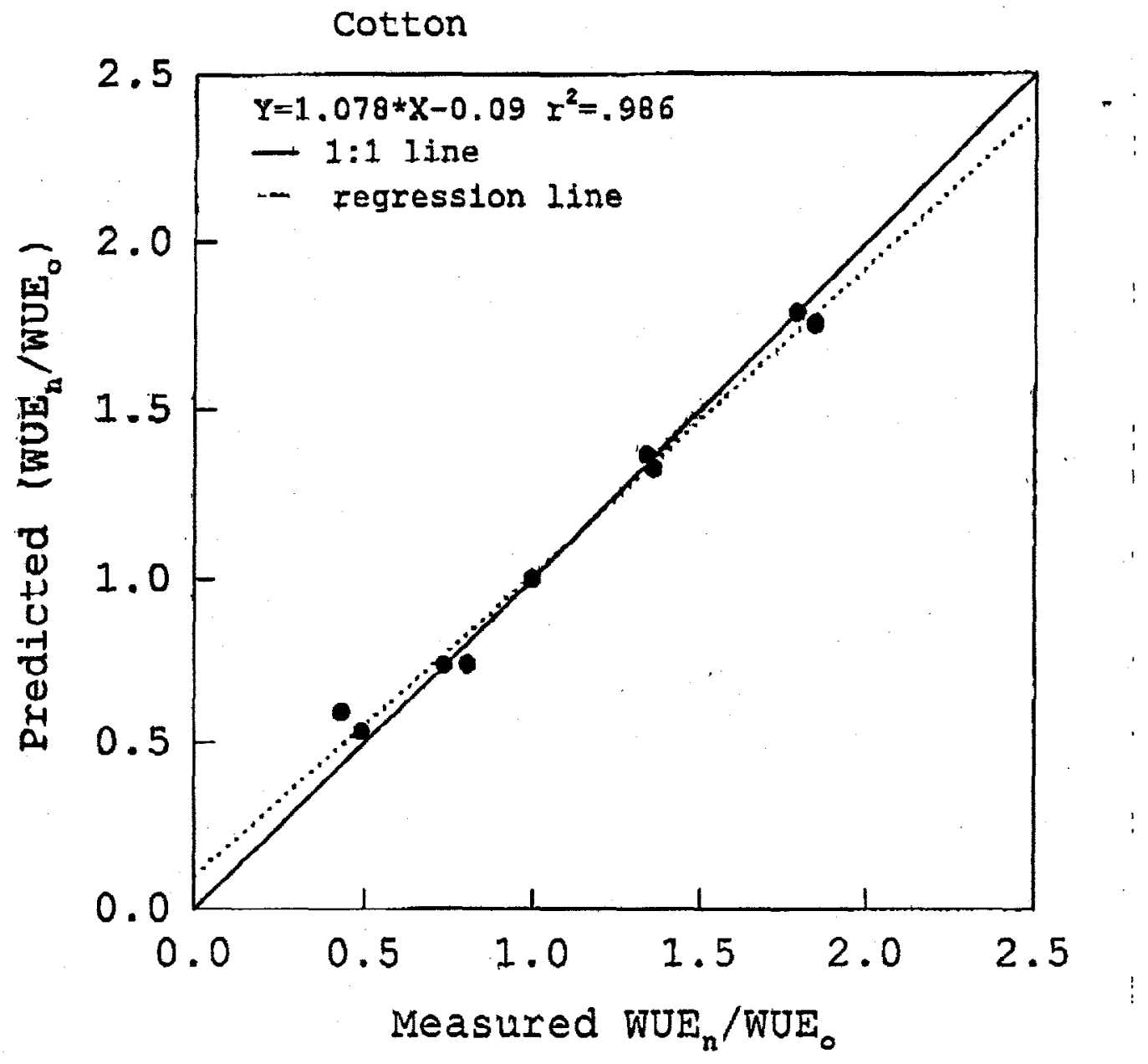

Fig. 11. Comparison of predicted relative change with the measured relative change in leaf photosynthetic WUE of a cotton leaf effected by changes in $\mathrm{Ca}$. Relative change is given as the ratio of WUE under new $\mathrm{Ca}$ (WUEn) to WUE under the original $\mathrm{Ca}$ (WUEO). Prediction was made using Eq. 9 of Hsiao (1993) with DW celculated from the humidity and leaf temperature data for the determination of the A. vs. Ci curve of the leaf in a gas exchange chamber. Measured WUE was calculated as the ratio of measured rate of photosynthesis to transpiration. Original Ca was $360 \mu \mathrm{mol} \mathrm{mol}{ }^{-1}$. 


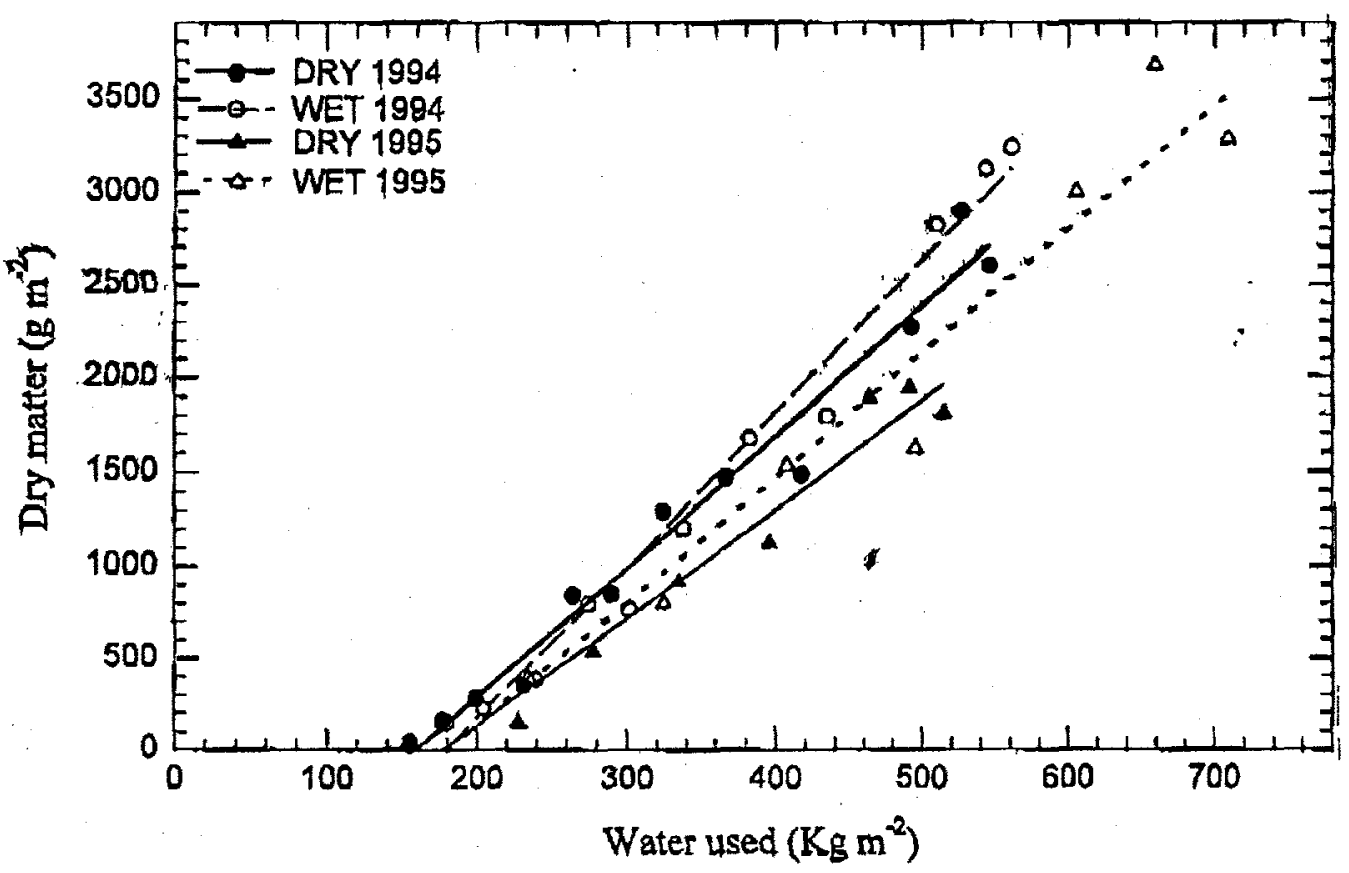

Fig. 12. Shoot dry matter of maize produced in the field obtained by sequential harvests vs. normalized cumulative evapotranspiration as measured by soil water balance. Soil water contents at different depths were measured with a neutron probe and ET was normlized for the daily reference ET measured by a weather station nearby. Lines are calculated by linear regression $\left(r^{2}>0.95\right)$ and their slopes indicate biomass water use efficiency (WUEme). 

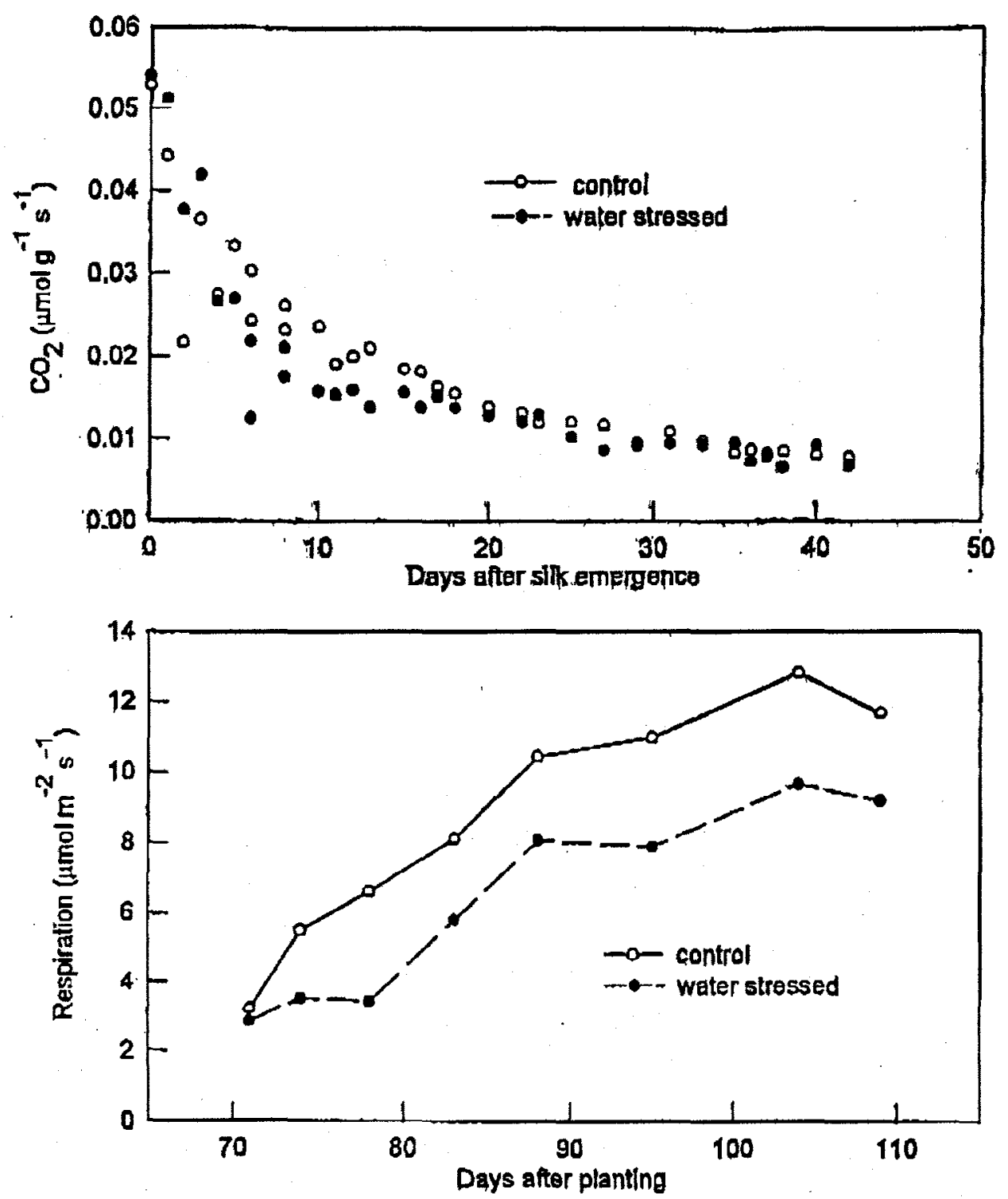

Fig. 13. Respiration rate of intact maize ears on plants of the dry (water stressed) and control treatment in the 1995 field experiment as a function of time, on a bisis of per unit of ear dry weight (top figure) or per unit of land area (bottom figure). Respiration was measured with a special mylar chamber sealed around the ear and connected to a LiCor 6200 photosynthesis apparanus. Each measurement lasted about $1 \mathrm{~min}$ and was at a temperature within $2-3^{\circ} \mathrm{C}$ of ambient. 
Fig. 14. Daily pattern of evapotranspiration (expressed in energy unit as negative $\lambda \mathrm{E}$ ), components of energy balance (sensible heat $H$, and net radiation $R n$ ), canopy photosynthesis (A), and canopy photosynthetic water use efficiency (WUE=A/E) of maize of the dry treatment and control (wet) in adjacent fields on 9/12/1995. Also shown are incident PAR, air temperature, and canopy temperature measured with an infrared thermometer. Data were obtained by the Bowen ratio/energy balance/CO2 gradient technique. Midday leaf water potential was $-1.63 \mathrm{MPa}$ and $-1.00 \mathrm{MPa}$, LAI was 2.2 and 4.8 and leaf nitrogen content was $1.6 \%$ and $2,2 \%$, respectively, for the dry treatment and control. 


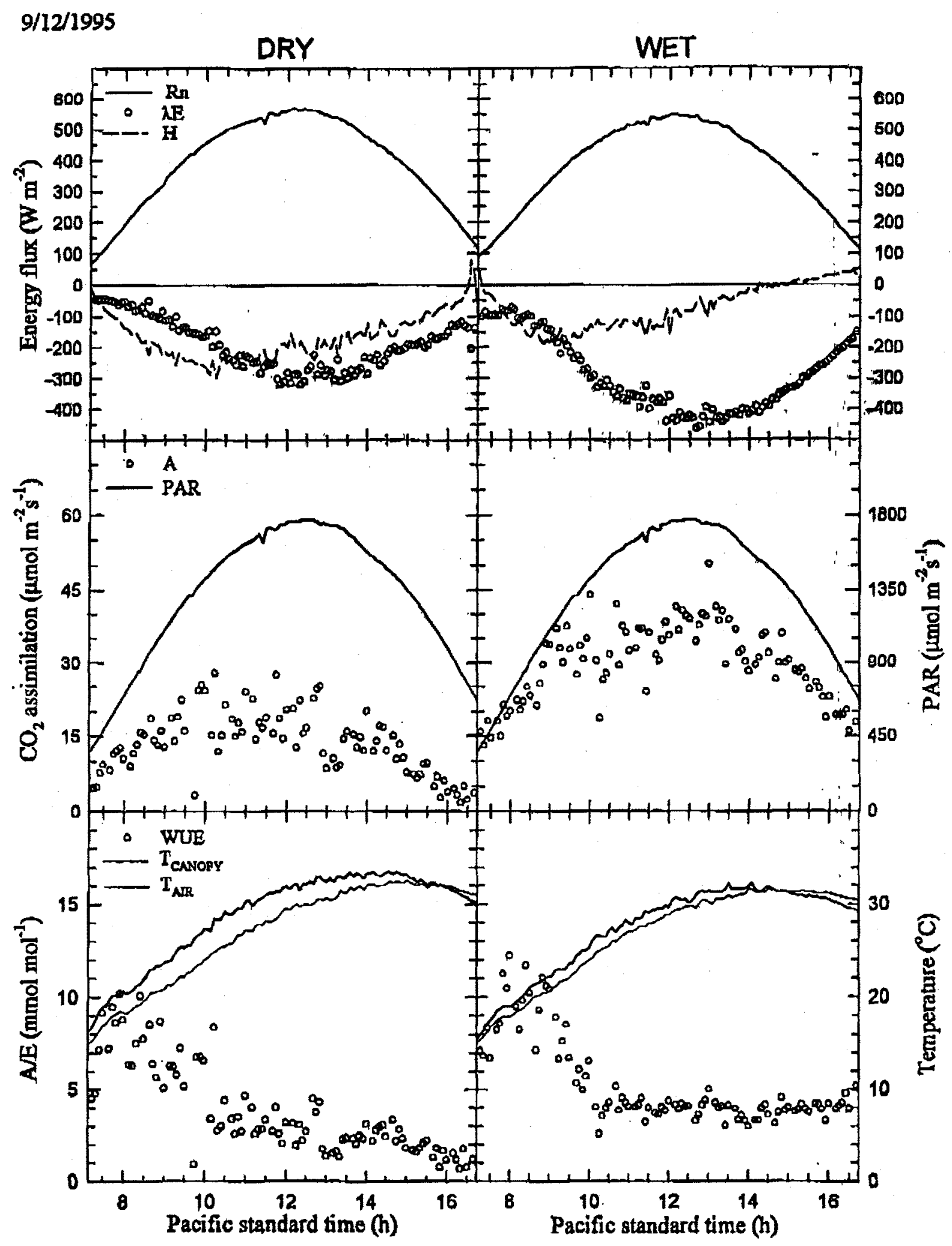



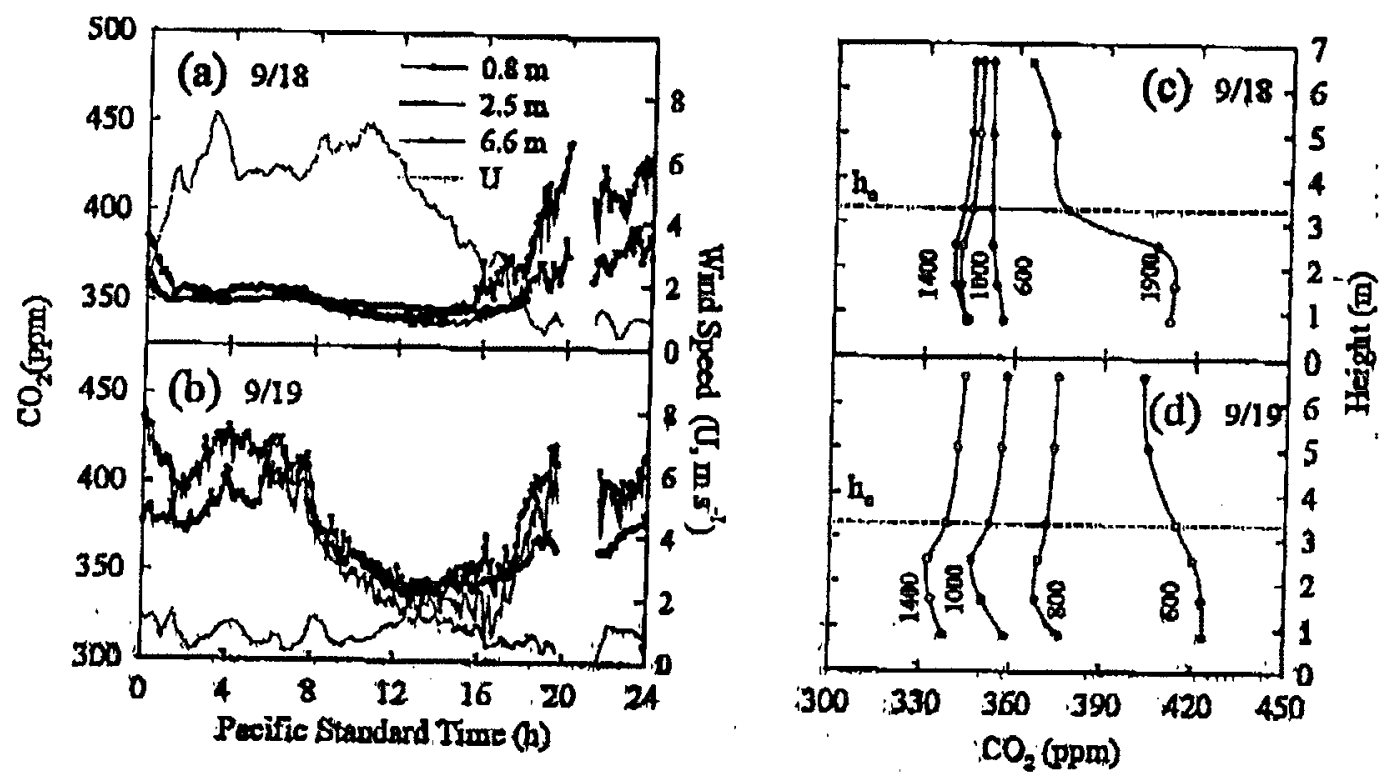

Figure 15. Samples of CO2 diumal variations and profiles on a windy day $(9 / 18 / 1996)$ and a calm day (9/19.1996) for a well irrigated maize filed in Davis, California. For clarity, 5 min mean $\mathrm{CO} 2$ data are shown only for three heights in $(a, c)$, and 30 min mean of profiles in $(b, d)$. Wind speed data (i.e. $U$ ), which aro the six points moving average on 5 min mean raw data, were obtained with low inertia cup anemometer at the height of $6 \mathrm{~m}$. Dashed lines in $(b, d)$ represent the canopy height. 